\title{
High Voltage Design Guidelines: A Timely Update
}

\author{
G. B. Hillard' and H. Kirkici ${ }^{2}$ \\ 'NASA Glenn Research Center, Cleveland OH, USA \\ ${ }^{2}$ Auburn University, Auburn AL, USA
}

\begin{abstract}
The evolving state of high voltage systems and their increasing use in the space program have called for a revision of the High Voltage Design Guidelines, Marshall Space Flight Center technical document MSFC-STD-531, originally issued September 1978 (previously 50 M05189b, October 1972). These guidelines deal in depth with issues relating to the specification of materials, particularly electrical insulation, as well as design practices and test methods. Emphasis is on corona and Paschen breakdown as well as plasma effects for Low Earth Orbiting systems. We will briefly review the history of these guidelines as well as their immediate predecessors and discuss their range of applicability. In addition, this document has served as the basis for several derived works that became focused, program-specific HV guidelines. We will briefly review two examples, guidelines prepared for the X-33 program and for the Space Shuttle Electric Auxiliary Power Unit (EAPU) upgrade.
\end{abstract}

\section{Introduction}

In the early days of the space program, electrical systems were largely based on the 28 volt standard inherited from the aircraft industry. As systems grew larger and more complex the introduction of high voltage components and systems led to design issues involving electrical breakdown.

As experience accumulated within industry and government, attempts were made to capture it with various design guidelines. As one such effort, the Marshall Space Flight Center (MSFC) began the development of a suitable guidelines document in the early 1970's. Originally issued as 50 M05189b, October 1972, it was upgraded to a MSFC standard and reissued as MSFC-STD-531 in September 1978.

By the late 1990s it was clear that STD-531 needed considerable revision to capture experience gained in the two decades since its issue. Two parallel efforts that involved specific projects provided an opportunity for synergy.

\section{$\mathrm{X}-\mathbf{3 3}$}

First, the $\mathrm{X}-33$ program requested that corona design guidelines be developed and issued in a timely manner to permit component testing. The team assembled for that effort reviewed the existing STD-531 and realized that, while obsolescent, it provided a structure for the needed guideline. As with any general guideline, STD 531 provided overall guidance by presenting the team with a systematic presentation of general principles. The purpose of the project-specific guideline was to apply those principles to the proposed design. This required the team to examine all high voltage subsystems and components, consider their packaging and environmental exposure, and evaluate the corona risk. The resulting document, designated as 604D0024 and issued in 1997, identified subsystems and components that were susceptible to corona discharge. It provided guidance to design engineers in their ongoing effort and identified critical parts which would require laboratory testing and certification. As the X-33 document was developed, a great deal of material relevant to STD-531 was amassed and archived.

\section{Electric Auxiliary Power Unit}

Second, by 1999 a major Space Shuttle upgrade was underway. This effort was to replace the hydrazine based Auxiliary Power Units (APU) that provide power for the hydraulic systems with electric batteries and pumps. The Electric Auxiliary Power Unit involves a 270 volt system located in the shuttle's aft compartment. The system will be operational from just before launch and will see air pressure drop from sea level to on-orbit conditions while powered. In addition to the possibility of corona discharge in air, the compartment will experience a helium purge during the operational timeline. Corona concerns led to the formation of a study group under the leadership of D.K. Hall at MSFC in Huntsville Alabama.

A guidelines document eventually titled "ELECTRIC AUXILIARY POWER UNIT CORONA DESIGN GUIDELINE" was developed and completed by the spring of 2000 . As with the X-33 effort, this required that the design be carefully considered against the general requirements laid down in STD 531. As part of the effort, the Johnson Space Center, which managed the project, realized that an update of STD 531 was required and agreed to fund both EAPU and STD 531 as part of a single project. Team composition for this effort included several key members of the X-33 team with several additions (see below).

We present here only a brief overview of STD 531.

This is a preprint or reprint of a paper intended for presentation at a conference. Because changes may be made before formal publication, this is made available with the understanding that it will not be cited or reproduced without the permission of the author. 


\section{Description}

The current document is about 140 pages of text plus another 48 pages of a little over 40 figures. Figures will incorporated into the text at the final edit since their presence slows the word processing software so much that it is almost unusable. The table of contents is a five level deep outline that requires 5 pages by itself. To briefly present the scope of the work, we will briefly describe each of the top level headings.

\section{Introduction}

In the first and smallest major section, we define various key terminology and the scope of the of the problem at hand. This includes a brief history of high voltage insulation with an overview of key materials employed. We define high voltage interactions with a careful distinction between the often confused terms corona and partial discharge. Finally, we introduce plasma interactions that affect high voltage systems operating in Low Earth Orbit (LEO).

\section{Environments}

The environments covered range from sea level conditions typical of a launch site to LEO. In major subsections, we first describe the natural environment. This includes both the neutral atmosphere and the plasma environment encountered in space. Next we discuss particulates, meteoroids and orbital debris, which is increasingly being recognized as a significant environmental component. After that, we introduce and discuss the contamination-induced environment. As is well know, outgassing can often be the single biggest factor in causing electrical breakdown. Finally, we discuss the electrical environment with an emphasis on triboelectric effects and material charging.

\section{Interactions}

In this section, the longest in the document, we begin with an overview of electric field configurations. Since breakdown depends critically on electric field strength, we review field dependence for standard configurations and give general guidelines for reducing field in practical designs.

We follow with a subsection on the breakdown of gases which includes Paschen's law, high frequency effects, multipactor phenomena, and flashover phenomena.

Breakdown in solids is treated next. We introduce the topic with background material on polarization, the dielectric constant, and dielectric strength. Along with some practical examples we discuss treeing, aging effects and the effect of temperature before moving into corona extinction voltage and its dependence on material and geometry.

The final subsection concerns plasma interactions. While an enormous field of study in its own right and the subject of dedicated documents, we present an overview designed to give the designer a basic understanding of plasma effects. The subject is introduced with background material on plasma current collection, resulting power loss, and the effect on spacecraft potential. A brief overview of mitigation techniques follows along with a discussion of available modeling tools designed to predict voltages on spacecraft surfaces and electric fields in nearby space. A fairly comprehensive series of topics are then treated under solar array arcing. This subject is still an active area of research and is more empirical in nature but a number of useful guidelines have emerged from recent experience.

\section{Design Applications}

This subsection deals with the application of the general principles and guidelines introduced previously. It begins by breaking the voltage regime encountered into several subregions and noting the general differences each has with respect to voltage breakdown. Following are individual treatments of solid insulation, packaging, interconnection systems, and a survey of parts an components. The section ends with a treatment of printed circuit boards and guidelines on grounding and bonding.

\section{Testing}

The final section concerns testing as applicable to high voltage breakdown. It includes a general discussion of test procedures with a number of subtopics dealing with various detectors and sensors.

\section{Future Evolution}

STD 531 is considerd to be a "living document" subject to revision as required. While the team that was assembled for the effort reported here is not funded for future work, it is anticipated that the individual members will be available should a need arise. There are two general situations that might lead to a renewal of this effort.

First, a specific project might require a high voltage design guideline, much as EAPU did, and fund its development. Since STD 531 would form the tremplate for the effort, updates could be made at that time.

Second, advances in basic understanding might require that STD 531 be revised. As one example, part of EAPU will involve a 270 volt $20 \mathrm{kHz}$ square wave. 
While corona and associated effects are reasonably well known for dc and $60 \mathrm{~Hz}$ sine wave power, high frequency pulsed power is much less well understood and even less is known about plasma effects for systems using such a power profile. The EAPU project had originally hoped to fund experiments in gas breakdown under these conditions but was unable to do so because of funding limitations. Nevertheless, the attractive features of such power sources will result in their increasing use and the inevitable observations of corona effects will result in support for further research. The resulting knowledge will be incorporated into STD 531 , and the means of assembling and funding the team required would have to be worked at that time.

\section{Team Composition}

The team assembled for the effort described here was chartered by Brad Irlbeck from the Johnson Space Center, project manager for EAPU. The team consisted of five members

D.K. Hall, MSFC - Team Lead and senior test engineer. D.K. was also the team lead for both the X-33 and EAPU documents.

Bill Dunbar, consultant. Bill was, until his untimely death late in the project, the senior technical consultant.
Well known in the corona community, he was a recognized expert in all aspects of gas breakdown phenomenon and high voltage power systems.

Hulya Kirkici, Professor. Hulya, from Auburn University in Aubum Alabama, is an electrical engineer with a well-known expertise in corona problems, especially in RF efects.

Dan Schweickart, U.S. Air Force. Dan is a senior scientist with the Air Force Research Lab at Wright Patterson Air Force Base in Dayton Ohio. A leader in the corona community, Dan is the Air Force's leading expert in corona testing.

Barry Hillard, NASA. With the Glenn Research Center in Cleveland Ohio, Barry comes from a background in spacecraft charging and space plasma interactions. He was responsible for the plasma effects portions of the effort.

Author address: G. Barry Hillard, NASA, John $H$. Glenn Research Center, 21000 Brookpark Road, Cleveland, $\mathrm{OH}, \mathrm{USA} 44135$, Email: hillard@grc.nasa.gov 